\title{
鄂尔多斯高原巴汗淖湖泊记录的全新世气候变化
}

\section{郭兰兰 ${ }^{\circledR}$ 冯兆东 ${ }^{\circledR} \quad$ 李心清 $^{\ominus} \quad$ 刘连友 ${ }^{\circledR} \quad$ 王丽霞 ${ }^{\oplus}$}

(1) 北京师范大学环境演变与自然灾害教育部重点实验室, 北京 100875; (2) 兰州大学西部环境教育部重点实验室, 兰州 730000; (3)中国科学院地球化学研究所, 贵阳 550002; (4)辽宁省环境监测中心站, 沈阳 110031. E-mail: 11guo@ires.cn)

\begin{abstract}
摘要 通过对鄂尔多斯高原中部的巴汗淖湖泊沉积物的环境代用指标综合分析, 以 $\mathrm{AMS}{ }^{14} \mathrm{C}$ 测年为基 础, 重建了鄂尔多斯高原全新世的气候变化历史. 分析结果显示: 鄂尔多斯高原约 $7.65{ }^{14} \mathrm{C} \mathrm{ka} \mathrm{BP}$ 前气 候寒冷干燥; $7.65 \sim 5.40{ }^{14} \mathrm{C} \mathrm{ka} \mathrm{BP}$ 气候温暖湿润, 其中 $7.65 \sim 6.70{ }^{14} \mathrm{C} \mathrm{ka} \mathrm{BP}$ 气候相对暖湿, 以湿度条件 改善更明显, 随后 $6.70 \sim 6.20{ }^{14} \mathrm{C} \mathrm{ka} \mathrm{BP}$ 气候偏暖干, $6.20 \sim 5.40{ }^{14} \mathrm{C} \mathrm{ka}$ BP 研究区温湿组合状况最佳; $5.40{ }^{14} \mathrm{C}$ ka BP 后鄂尔多斯高原总体向干凉方向发展, 但在 $4.70 \sim 4.60{ }^{14} \mathrm{C} \mathrm{ka} \mathrm{BP}$ 和 $4.20 \sim 3.70{ }^{14} \mathrm{C} \mathrm{ka} \mathrm{BP}$ 出现两个明显的相对湿润时期; 约 $3.70{ }^{14} \mathrm{C} \mathrm{ka} \mathrm{BP}$ 后巴汗淖湖泊完全干涸.
\end{abstract}

关键词 全新世 鄂尔多斯高原 湖泊沉积 气候变化

未来气候变化是自然因素与人为因素共同作用 的结果. 要理解过去人类对气候的影响和预测未来 人类影响下的气候变化, 必须首先明确气候变化的 自然规律 ${ }^{[1,2]}$. 全新世作为距今最近的一个间冰期, 其气候变化规律既是未来气候变化的背景, 也最有

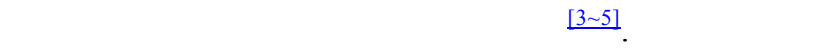
原大部分属于中国的沙漠-黄土过渡带, 位于东亚夏 季风区的西北缘, 是研究全球变化的理想区域 ${ }^{[6]}$. 在 过去的 20 年里, 不少学者对鄂尔多斯高原风成序列 记录的古气候和古环境进行了比较深入的研究 ${ }^{[7 \sim 13]}$, 但多数研究仅涉及晚更新世, 对全新世的深入研究 一直受地质记录和测年技术和材料的限制 [14]. 湖泊 沉积一直被认为是比较理想的全新世气候变化载体. 虽然鄂尔多斯高原湖泊广泛分布, 但除盐海子 ${ }^{[15]}$ 外, 尚未见到来自其他湖泊关于全新世气候重建的报道. 本文选取鄂尔多斯高原封闭湖泊一巴汗淖, 对其沉 积物进行多指标气候分析, 并结合可靠的 $\mathrm{AMS}^{14} \mathrm{C}$ 年 代序列重建鄂尔多斯高原全新世以来的气候变化历 史, 期望藉此理解鄂尔多斯高原的全新世气候变化 规律, 并为理解大尺度的全新世气候变化机制提供 区域证据.

\section{1 研究区概况}

巴汗淖 $\left(109^{\circ} 16^{\prime} \mathrm{E}, 39^{\circ} 19^{\prime} \mathrm{N}\right)$ 位于鄂尔多斯高原中 部, 海拔高度 $1278 \mathrm{~m}$, 隶属于内蒙古自治区伊克昭 盟乌审旗(图 1(a)). 地带性植被为干旱-半干旱荒漠草
原，区内全年大部分时间为西北季风控制，气候寒冷 干燥, 但东南季风仍可以影响到本区域, 并对区域的 降水起决定作用. 研究区年均温度 $6 \sim 9^{\circ} \mathrm{C}$, 年平均降 水量 $200 \sim 300 \mathrm{~mm}$, 主要集中在 $6 \sim 9$ 月且降水强度 较大; 年潜蒸发量达 $2500 \sim 3000 \mathrm{~mm}$, 是年均降水量 的 10 倍, 区域干燥度 $3.5 \sim 4.0$ 通, .17].

鄂尔多斯高原广泛分布有第四纪晚期以来由风 蚀和流水侵蚀洼地发展而来的封闭型小湖泊, 巴汗 淖即为古河谷侵蚀而成的 7 个串珠状湖盆的最末一 个(图 1(b), 湖 7), 湖盆面积 $26.50 \mathrm{~km}^{2}$, 基底为连续而 完整的下白严统砂岩; 湖盆封闭, 以大气降水为主要 补给水源, 此外浅层潜水和泉水也为湖泊提供了一 定的水源. 下白严统砂岩中丰富的钠钙质碳酸盐是 巴汗淖湖泊盐类的重要物质来源, 湖泊主要沉积盐 类有天然碱、泡碱、针碳钠钙石、水碱、钙水碱等 ${ }^{[18]}$.

\section{2 样品采集及年代序列的建立}

巴汗淖湖芯样品采集于 2002 年 7 月, 采用国产 机械钻配合套管采样. 通过岩性对比衔接取得 $5.3 \mathrm{~m}$ 连续样芯 1 支及顶部 $2 \mathrm{~m}$ 短样芯 2 支. 岩芯底部 435 $530 \mathrm{~cm}$ 为灰黑色细砂过渡到中粗砂; $350 \sim 435 \mathrm{~cm}$ 为 黑色黏土; $300 \sim 350 \mathrm{~cm}$ 为黑色粉砂质黏土; $230 \sim$ $300 \mathrm{~cm}$ 为灰黑色富碳酸盐黏土质纹层; $80 \sim 230 \mathrm{~cm}$ 为棕红色粉砂质黏土; $80 \mathrm{~cm}$ 以上沉积物为棕色中粗 砂(图 2). 所有样品就地按 $2 \mathrm{~cm}$ 连续采样, 分样袋密 封后运回实验室冷冻保存. 


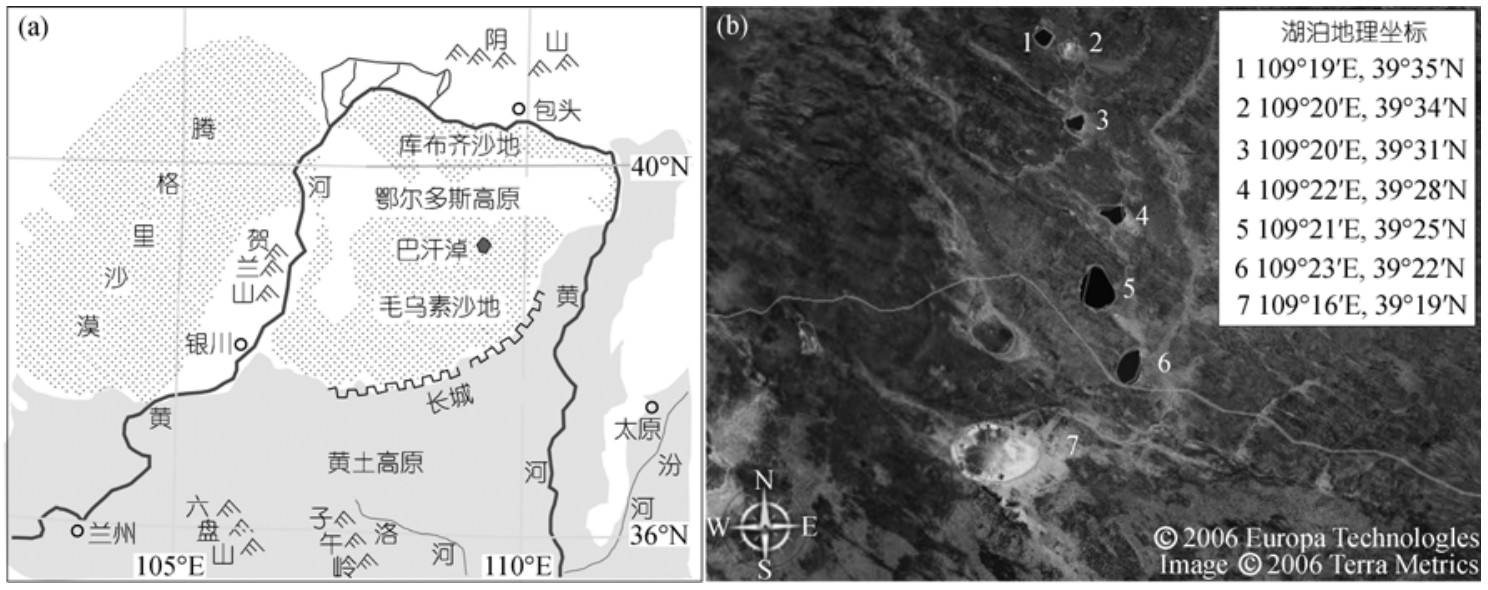

图 1 巴汗淖位置图(a)和串珠状湖盆的卫星遥感图像(b)

湖泊 7 为巴汗淖

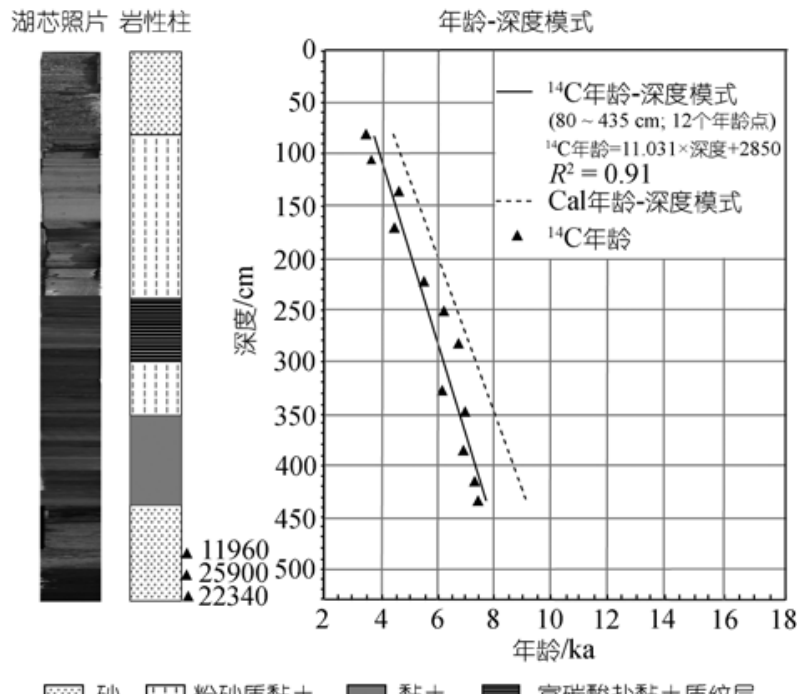

图 2 巴汗淖湖芯照片、岩性柱及年代-深度模式

巴汗淖湖芯 $80 \sim 530 \mathrm{~cm}$ 段共选取 16 个 $\mathrm{AMS}{ }^{14} \mathrm{C}$ 年龄测试样品, 分别由美国 Beta Analytic Inc.(Beta 编 号)实验室和亚利桑那大学 NSF AMS Facility(AA 编 号)实验室测试完成, 测年材料选用沉积物全样, 其 中 BN12 样品不足, 没有分析结果(表 1).

巴汗淖全部测年结果显示存在年代倒转现象, 其中在湖相地层发生倒转的 3 个年龄 $(\mathrm{BN} 6, \mathrm{BN} 8$, BN14)均为Beta实验室与NSF实验室测年结果交叉的 部分, 且均表现为Beta实验室测年结果偏年轻; 进一 步分析显示两实验室各自的测年结果除底部砂层外 均不存在倒转情况, 但Beta实验室测年结果似乎较
NSF实验室总体偏年轻(表 1); 因此，推断巴汗淖湖 相地层部分测年结果倒转原因在于实验室的系统误 差. 不同实验室存在系统误差的原因需进一步研究. 遵照客观和谨慎的原则, 选用所有的测年数据线性 回归建立本文的年代序列框架. 巴汗淖湖芯岩性特 征显示深度 $435 \mathrm{~cm}$ 上下沉积物岩性差别显著, 年代深度曲线也显示 $435 \mathrm{~cm}$ 上下沉积速率发生明显变化, 据此将巴汗淖年龄模式分 $80 \sim 435,435 \sim 530 \mathrm{~cm}$ 两 段考虑: 深 $80 \sim 435 \mathrm{~cm}$ 段为由黏土和粉砂质黏土组 成的细粒湖相沉积, 其线性拟和数据与原始数据相 关系数很高 $\left(R^{2}=0.91\right.$, 图 2); $435 \sim 530 \mathrm{~cm}$ 段沉积物为

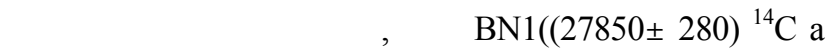
BP, 深 $506 \mathrm{~cm}), \mathrm{BN} 2\left((24290 \pm 537){ }^{14} \mathrm{C}\right.$ a BP, 深 527 $\mathrm{cm})$ 年代发生倒转, 可能表明末次冰期时巴汗淖所处 位置的地表是极为不稳定的(沙丘?), 导致其平均沉 积速率偏低, 生物扰动使年代发生倒转. 在建立湖芯 年代序列时, C-14 年龄的“碳库效应”的确定较困难. 巴汗淖湖芯的表层 $80 \mathrm{~cm}$ 为非湖相沉积, 因而无法用 C-14 测量表层样的方法进行“碳库效应”校正. 已有 研究表明内蒙古湖泊的碳库效应一般为 $1000 \sim 2000$ $\mathrm{a}^{[19]}$, 来自巴汗淖南 $100 \mathrm{~km}$ 处盐湖苟池的碳库效应校 正结果显示碳库效应为 $1935 \mathrm{a}^{[20]}$, 最近与巴汗淖相 距不到 $1 \mathrm{~km}$ 的染盖淖(图 1(b), 湖 6)所得的碳库效应 为 $1950 \mathrm{a}$ (张成君末发表资料). 我们认为将 $1950 \mathrm{a}$ 作 为巴汗淖碳库效应值统一扣除是现有研究条件下比 较可行的做法, 因为在巴汗淖被湖水稳定占领期间 $\left(7.65^{\circ / 03} 3.70^{52}{ }^{14} \mathrm{C}^{8} \mathrm{ka} \quad \mathrm{B} P\right.$ )，注入巴汗淖 (相 
表 1 巴汗淖测年结果

\begin{tabular}{|c|c|c|c|c|c|c|}
\hline 实验室编号 & 样号 & 深度/cm & ${ }^{13} \mathrm{C} /{ }^{12} \mathrm{C} / \% 0$ & $\mathrm{AMS}{ }^{14} \mathrm{C}$ 年龄 $/ \mathrm{a}$ & $\mathrm{Cal}$ 年龄 $(2 \sigma)$ & 测年材料 \\
\hline Beta-181621 & BN16 & 81 & -23.8 & $5440 \pm 40$ & $6356 \sim 6223$ & 沉积物全样 \\
\hline AA56715 & $\mathrm{BN} 15$ & 103 & -8.5 & $5549 \pm 42$ & $6460 \sim 6331$ & 沉积物全样 \\
\hline AA56714 & $\mathrm{BN} 14$ & 133 & -12 & $6538 \pm 44$ & $7560 \sim 7465$ & 沉积物全样 \\
\hline Beta- 181620 & BN13 & 167 & -24.2 & $6340 \pm 40$ & $7381 \sim 7255$ & 沉积物全样 \\
\hline Beta-181619 & BN11 & 227 & -24.2 & $7500 \pm 40$ & $8435 \sim 8228$ & 沉积物全样 \\
\hline Beta-171831 & $\mathrm{BN} 10$ & 250 & -25.7 & $8130 \pm 50$ & $9206 \sim 9046$ & 沉积物全样 \\
\hline AA51969 & BN9 & 283 & -13.1 & $8631 \pm 52$ & $9806 \sim 9576$ & 沉积物全样 \\
\hline Beta-171830 & $\mathrm{BN} 8$ & 327 & -24.9 & $7960 \pm 40$ & $9041 \sim 8746$ & 沉积物全样 \\
\hline AA51968 & BN7 & 345 & -12.4 & $9038 \pm 57$ & $10334 \sim 10162$ & 沉积物全样 \\
\hline Beta-171829 & BN6 & 385 & -24.8 & $8850 \pm 40$ & $9606 \sim 9523$ & 沉积物全样 \\
\hline AA51967 & BN5 & 415 & -11 & $9303 \pm 64$ & $10652 \sim 10408$ & 沉积物全样 \\
\hline AA51966 & BN4 & 431 & -10.2 & $9338 \pm 57$ & $10743 \sim 10430$ & 沉积物全样 \\
\hline Beta-171828 & $\mathrm{BN} 3$ & 487 & -23.8 & $13910 \pm 70$ & $17244 \sim 16260$ & 沉积物全样 \\
\hline AA51965 & $\mathrm{BN} 2$ & 506 & -3.2 & $27850 \pm 280$ & & 沉积物全样 \\
\hline AA51964 & BN1 & 527 & -6.5 & $24290 \pm 537$ & & 沉积物全样 \\
\hline
\end{tabular}

通的 7 个串珠状湖的第 7 个)水是来自染盖淖的(相通 的 7 个串珠状湖的第 6 个). 即影响这两个湖(巴汗淖 和染盖淖)有机质碳库效应的水化学因子应该是一样 的. $80 \sim 435 \mathrm{~cm}$ 测年数据扣除 $1950 \mathrm{a}$ 的碳库效应后进 行线性拟合得到巴汗淖 ${ }^{14} \mathrm{C}$ 年龄-深度曲线(图 2 实线); 将 ${ }^{14} \mathrm{C}$ 年代数据用Stuiver等人 ${ }^{[21]}$ 提供的CALIB rev4.4 程序校正为日历年龄 $(\mathrm{Cal})$ 得到日历年龄-深度曲线 (图 2 虚线). 该年龄-深度模式下得到沉积速率突变处 $435 \mathrm{~cm}$ 沉积年龄为 $7650{ }^{14} \mathrm{C}$ a BP, 深 $80 \sim 435 \mathrm{~cm}$ 湖 相沉积物形成的年龄范围为 $3700 \sim 7650{ }^{14} \mathrm{C}$ a BP, 而 $435 \sim 530 \mathrm{~cm}$ 为早全新世至晚更新世沉积物. 由于区 内已发表的风成沉积剖面多用 ${ }^{14} \mathrm{C}$ 年代, 为便于比较, 文中给出了对应的 ${ }^{14} \mathrm{C}$ 年龄，用 $\mathrm{Ca}$ 标识特指日历年 龄.

\section{3 分析方法}

对巴汗淖湖泊沉积物进行了沉积物平均粒径、碳 酸盐含量、有机碳同位素 $\left(\delta^{13} \mathrm{C}_{\mathrm{org}}\right)$ 及碳酸盐碳 $\left(\delta^{13} \mathrm{C}_{\mathrm{car}}\right)$ 和氧同位素 $\left(\delta^{18} \mathrm{O}_{\mathrm{car}}\right)$ 、总有机碳含量 $(\mathrm{TOC})$ 、碳氮比 $(\mathrm{C} / \mathrm{N})$ 等代用指标的分析. 受样品数量限制, $\mathrm{C} / \mathrm{N}$ 指标 间隔 $35 \mathrm{~cm}$ 测定, 其他代用指标均间隔 $2 \mathrm{~cm}$ 测样, 所 有实验均在兰州大学西部环境教育部重点实验室完 成.

沉积物粒度由英国 MALVEN 公司产的 Mastersizer 2000 型激光粒度仪完成. 测量前加入 10 $\mathrm{mL}$ 浓度为 $10 \%$ 的 $\mathrm{H}_{2} \mathrm{O}_{2}$ 和 $10 \mathrm{~mL}$ 浓度为 $10 \%$ 的稀 $\mathrm{HCl}$ 分别去除样品有机质及碳酸盐, 并加入 $10 \mathrm{~mL}$ 分 散剂(浓度为 $5 \%$ 的六偏磷酸钠溶液)超声波振荡. 碳 酸盐含量采用气量法测试, 取适量样品 $60^{\circ} \mathrm{C}$ 烘干研
碎过 120 目筛, 称取 $0.1 \sim 0.5 \mathrm{~g}$ 干样在封闭系统中与 浓度为 $10 \%$ 的稀 $\mathrm{HCl}$ 发生反应释放 $\mathrm{CO}_{2}$ 气体, 通过 $\mathrm{CO}_{2}$ 气体体积计算碳酸盐的含量.

有机碳同位素与碳酸盐碳、氧同位素测定由德国 Finnigan MAT 公司产 Delta-Plus 稳定同位素质谱分析 仪完成. 有机碳同位素样品前处理采用纯氧燃烧-冷 冻法, 取样品 $3 \sim 5 \mathrm{~g}$ 加入 $80 \mathrm{~mL}$ 浓度为 $15 \%$ 的稀 $\mathrm{HCl}$ 静置 $24 \mathrm{~h}$ 去除样品碳酸盐, 蒸馏水冲洗至中性, $60^{\circ} \mathrm{C}$ 下烘干研碎过 120 目篮, $800^{\circ} \mathrm{C}$ 真空系统下通氧气灼 烧 $8 \sim 10 \mathrm{~min}$, 酒精液氮和纯液氮冷阱纯化收集 $\mathrm{CO}_{2}$ 气体供质谱议分析. 碳酸盐碳、氧同位素样品前处理 分析采用磷酸法, 取适量样品烘干研磨过 120 目篮, 与过饱和磷酸在 $75^{\circ} \mathrm{C}$ 下恒温反应 $30 \mathrm{~min}$, 纯化收集 $\mathrm{CO}_{2}$ 气体. 同位素测定结果均以 PDB 标准表示.

有机碳总量测定采用重铬酸钾-硫酸氧化法, 样 品 $60^{\circ} \mathrm{C}$ 下烘干研碎过 120 目篮, 准确称取 $0.1 \sim 0.5 \mathrm{~g}$ 样品加入 $0.0027 \mathrm{~mol} / \mathrm{L}$ 重铬酸钾标准溶液及浓度为 $98 \%$ 的浓硫酸溶液各 $5 \mathrm{~mL}, 170 \sim 180^{\circ} \mathrm{C}$ 下加热 $5 \mathrm{~min}$, 冷却后加邻啡罗啉指示剂用 $0.0013 \mathrm{~mol} / \mathrm{L}$ 硫酸亚铁 溶液滴定, 由滴定消耗的硫酸亚铁溶液体积计算得 到样品的 TOC 值. C/N 值由德国 Elementar 公司生产 的 Vairo EL III 型元素分析仪测试完成, 前处理过程与 有机碳同位素相同.

\section{4 结果与讨论}

\section{1 代用指标意义及分析结果}

巴汗淖各气候代用指标实验分析结果见图 3.

湖泊沉积物粒度分布主要由湖水物理能量控制, 同时受流域状况(如径流变化、源区物质、生物活动 


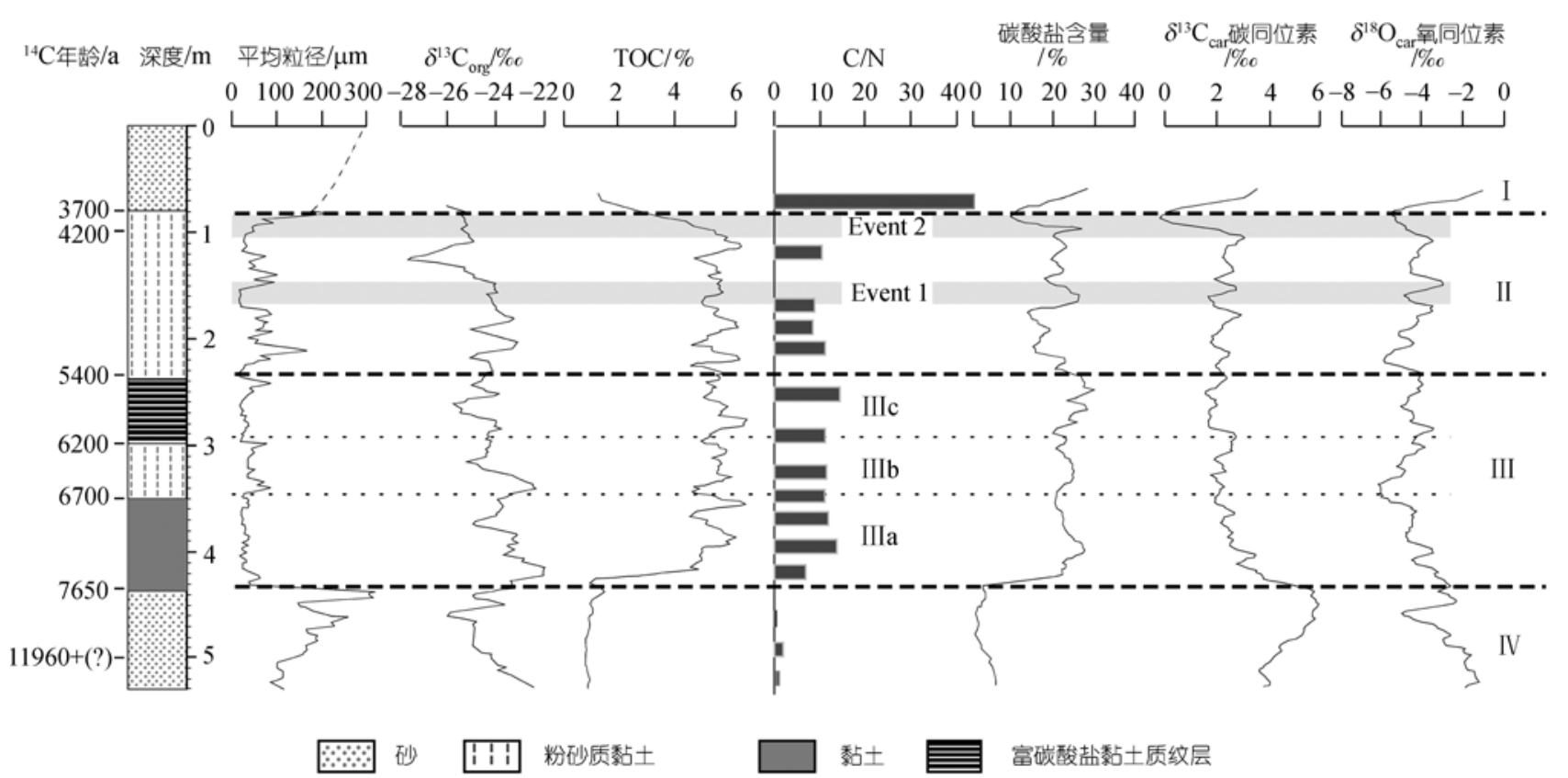

图 3 巴汗淖湖芯岩性柱、平均粒径、有机碳同位素、总有机碳含量、碳氮比值 $(\mathrm{C} / \mathrm{N})$ 、碳酸盐含量、碳酸盐碳同位素、 碳酸盐氧同位素分析结果

等)影响 [22]. 在长时间尺度较低分辨率(百年、千年) 的古气候研究中, 封闭湖泊沉积物粒度变化主要受 湖泊水位影响 ${ }^{[23]}$, 间接反映了湖区有效湿度. 湖泊 沉积物有机碳同位素组成受有机质来源(包括外源陆 生高等植物和内源水生植物)和湖水化学性质等因素 控制 [24]. 由于陆生高等植物 $\mathrm{C} / \mathrm{N}$ 值通常为 $20 \sim 30$, 甚 至高达 $45 \sim 50$; 而水生植物 $\mathrm{C} / \mathrm{N}$ 值仅为 $5 \sim 12$, 通常 $<10$, 因此 $\mathrm{C} / \mathrm{N}$ 值常用于辅助辨别湖泊有机质来源 [24,25]. 在干旱半干旱区地表植被发育较差的情况下, 湖芯 $\delta^{13} \mathrm{C}_{\mathrm{org}}$ 值主要取决于内源有机质中沉水植物 (以 水中溶解 $\mathrm{CO}_{2}$ 为碳源, $\delta^{13} \mathrm{C}$ 值在 $-20 \%$ - 12\%o之间) 与挺水植物 (以大气中 $\mathrm{CO}_{2}$ 为碳源, $\delta^{13} \mathrm{C}$ 值在 $-37 \%$ $-24 \% 0$ 之间)的相对比重 ${ }^{[25 ~ 27]}$, 也间接反映了湖泊水 位和湖区有效湿度变化, 在这种情况下同粒度指标 可相互对比, 巴汗淖实验分析结果证实了这一点. 结 果显示, 除顶部异常值和局部 $\mathrm{C} / \mathrm{N}$ 值较高(深 230 $300 \mathrm{~cm}$ 段 $\mathrm{C} / \mathrm{N}$ 值为 14 )外, 巴汗淖湖芯 $\mathrm{C} / \mathrm{N}$ 值整体低于 12, 指示湖泊有机质主要来源于内源水生植物. 巴汗 淖湖芯平均粒径分布在 $11 \sim 338 \mu \mathrm{m}$ 之间, $\delta^{13} \mathrm{C}_{\mathrm{org}}$ 值 分布在-28\%o - 21\% 之间, 两条曲线基本呈反相变 化. 深 $435 \sim 530,300 \sim 350,80 \sim 230 \mathrm{~cm}$ 湖芯平均粒 径高值同 $\delta^{13} \mathrm{C}_{\mathrm{org}}$ 低值所指示的挺水植物比重较大相
对应，二者共同指示了低湖面期; 深 $350 \sim 435 \mathrm{~cm}$ 湖 芯平均粒径低值与 $\delta^{13} \mathrm{C}_{\mathrm{org}}$ 高值所指示的沉水植物比 重较大相对应, 反映了一个高湖面期. 需要指出的是 深 $230 \sim 300 \mathrm{~cm}$ 段湖芯粒径较小, 但 $\delta^{13} \mathrm{C}_{\mathrm{org}}$ 值并未因 水位上升沉水植物增加而增大, 对应于湖芯 $\mathrm{C} / \mathrm{N}$ 最高 值段, 即该段陆源高等植物输入量最高. 现代表土同 位素研究显示, 区内表土有机质组成位于 $\mathrm{C}_{3}$ 植物范 围 ${ }^{[28]}$, 碳同位素偏轻的陆源有机质的大量输入可能 是造成上述提到的该段湖芯 $\delta^{13} \mathrm{C}_{\mathrm{org}}$ 值偏低的主要原 因. 类似的情况还发生在深 $400 \mathrm{~cm}, \mathrm{C} / \mathrm{N}$ 值增大指示 陆源输入有机质增加, 湖芯 $\delta^{13} \mathrm{C}_{\mathrm{org}}$ 值在总体较高的背 景下向负值方向偏移.

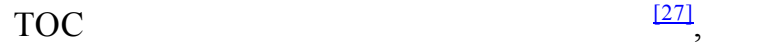
合 $\mathrm{C} / \mathrm{N}$ 指标, 可将巴汗淖湖芯有机碳含量变化以 80 , $435 \mathrm{~cm}$ 为界分三段讨论: $435 \mathrm{~cm}$ 以下 TOC值 $<1 \%$, 对 应 $\mathrm{C} / \mathrm{N}$ 值 $<2$, 表明湖芯有机质可能来源于湖泊浮游 生物, 湖区生产力水平极低但湖泊可能并未干涸; 深 $80 \sim 435 \mathrm{~cm}$ 段TOC值上升到 $5 \%$, 相应的 C/N值位于 8 $\sim 14$ 之间, 指示陆源入湖有机质增加, 流域植被较好, 且以 $230 \mathrm{~cm}$ 为界, 下半段 $\mathrm{C} / \mathrm{N}$ 值整体高于上半段; 80 $\mathrm{cm}$ 以上TOC快速降至 $1 \%$, 指示湖区生产力下降, 该 段 $\mathrm{C} / \mathrm{N}$ 值异常升至 43 . 
巴汗淖湖泊沉积物矿物分析显示沉积物中的碳 酸盐矿物以方解石和低镁方解石为主, 是化学沉积 形成的自生碳酸盐矿物. 湖泊中生物活动和湖泊物 理化学性质(如湖水温度、硬度、 $\mathrm{CO}_{2}$ 的逸出和溶解 等)变化均有可能导致湖水中碳酸盐过饱和而使碳酸 盐淀积 ${ }^{[29,30]}$. 巴汗淖地处半干旱区, 湖泊生产力水平 较低, 生物因素影响较小; 引起湖泊碳酸盐沉淀的最 主要因素是温度: 高温导致的碳酸盐溶解度降低、湖 水过饱和系数增大及高温蒸发作用使湖水中 $\mathrm{Ca}^{2+}$ 和 $\mathrm{HCO}_{3}{ }^{-}$离子浓度增大等因素均会导致碳酸盐沉淀 [27,29]. 巴汗淖碳酸盐含量分布在 3\% 30\%之间, 其中 $435 \mathrm{~cm}$ 以下最低, 除温度较低外, 砂质沉积物不利于 碳酸盐保存及石英矿物对碳酸盐的稀释作用等都可 能是该段碳酸盐低值的影响因素. 深 $230 \sim 435 \mathrm{~cm}$ 段 较高碳酸盐含量指示湖区温度较高, $230 \sim 300 \mathrm{~cm}$ 的 碳酸盐含量峰值可能指示该时段为全新世的最高温 期; $100 \sim 230 \mathrm{~cm}$ 段碳酸盐含量整体减小, 指示温度 降低. 其中 $100 \sim 170$ 和 $80 \sim 100 \mathrm{~cm}$ 碳酸盐含量较前 回升可能指示了湖区气温升高.

湖泊自生碳酸盐氧同位素组成主要受温度和湖 泊水体氧同位素影响, 后者与区域降水量、蒸发量及 湖水滞留时间等因素均有关系 [30 32]. 在水体氧同位 素变化不大的环境中, 湖泊自生碳酸盐氧同位素主 要由温度控制. 但在干旱半干旱区蒸发作用强烈, 蒸 发量与降水量比率对封闭湖泊水体氧同位素和自生 碳酸盐氧同位素的组成影响显著 ${ }^{[31,32]}$. 湖泊自生碳 酸盐碳同位素则依赖于湖水中溶解 $\mathrm{CO}_{2}$ (TDIC) 的碳 同位素组成，受湖水滞留时间、封冻时间、硬度及湖 泊生产力等因素影响, 其中与湖水的硬度关系最为 密切 ${ }^{[33 ~ 35]}$. 湖水的硬度高, 湖水含有溶解大气 $\mathrm{CO}_{2}$ 量 少，碳酸盐富集重碳同位素. 碳酸盐碳、氧同位素同 步变化与干旱环境下具有长滞留时间的封闭湖泊有 关 ${ }^{[34]}$, 强烈蒸发作用下湖水富集重氧同位素，同时 使湖水浓缩水体变暖, 湖水盐度和硬度增大, $\mathrm{CO}_{2}$ 从 水体排出, TDIC富集重碳同位素, 并最终使碳酸盐富 集重碳同位素，两者同步减小则指示湖区蒸发作用 减弱或(且)湖区降雨量增加 ${ }^{[34,35]}$; 而碳酸盐碳、氧同 位素的反相变化可能表明温度对碳酸盐氧同位素的 控制更强 ${ }^{[36,37]}$. 巴汗淖湖芯 $\delta^{13} \mathrm{C}_{\mathrm{car}}$ 值在 $0 \sim 6 \%$ 之间 波动, $\delta^{18} \mathrm{O}_{\text {car }}$ 值在-6.5\%。 1.5\% 之间波动, 其中 $435 \sim$ 530 和 $230 \sim 300 \mathrm{~cm}$ 碳酸盐碳氧同位素反相变化, 前 者对应于碳酸盐含量最低值段(即可能代表湖区温度
最低), 而后者对应于碳酸盐含量最高值段(即可能代 表湖区温度最高). 湖芯的其他段碳酸盐碳、氧同位素 同步变化: $350 \sim 435,80 \sim 100 \mathrm{~cm}$ 二者同步减小指示 湖区蒸降比减小, 湖水淡化, $300 \sim 350,100 \sim 230 \mathrm{~cm}$ 二者同步增大指示湖区蒸降比增大, 湖水浓缩.

\section{2 全新世气候环境重建}

IV ? $\sim 7650{ }^{14} \mathrm{C}$ a BP $(530 \sim 435 \mathrm{~cm}$; 砂层 $)$

气候寒冷干燥. 沉积物由中粗砂组成, 持续增大 的沉积物粒径、逐渐减小的有机碳同位素和极低的总 有机碳含量共同指示湖区气候干燥和湖水位极低或 湖泊干涸. 但极小的 $\mathrm{C} / \mathrm{N}$ 值 $(<2)$ 似乎指示有机质来源 于水生浮游生物, 可能表明湖泊并非完全干涸. 该段 碳酸盐含量最低和碳酸盐 $\delta^{18} \mathrm{O}_{\mathrm{car}}$ 值的持续减小表明 湖区气温低且呈下降态势; 指示湖水盐度的碳酸盐 $\delta^{13} \mathrm{C}_{\mathrm{car}}$ 值较高且呈上升趋势, 也可能表明湖泊的干 涸过程.

III $7650 \sim 5400{ }^{14} \mathrm{C}$ a BP $(435 \sim 230 \mathrm{~cm}$; 湖相黏 土质沉积)

湖区气候温暖湿润。该段以稳定且较低的沉积 物粒径值、较高碳酸盐含量和有机碳含量为特点, 该 段可以分作 3 个亚段:

III a $7650 \sim 6700{ }^{14} \mathrm{C}$ a BP $(435 \sim 350 \mathrm{~cm}$; 湖相黏 土)

亚温暖湿润气候期. 沉积物粒径快速降至 $50 \mu \mathrm{m}$, 然后快速下降并保持在低值 $(<25 \mu \mathrm{m})$, 有机质 $\delta^{13} \mathrm{C}_{\mathrm{org}}$ 值增大 $(-23 \% 0)$, 共同指示湖水上升沉水植物增加, 湖区气候向湿润方向发展, 进入湖相沉积时期; 总有 机碳含量从 $2 \%$ 迅速增加至峰值 $(5 \% \sim 6 \%)$, 对应的 $\mathrm{C} / \mathrm{N}$ 值增至 12 , 表明湖区生产力提高, 沉积物中有机 质部分来源于陆生高等植物但仍以水生浮游植物为 主; 湖芯碳酸盐含量升至 $20 \%$ 并在 $420 \mathrm{~cm}$ 处出现一 窄峰 $(25 \%)$ 指示气温较高; 碳酸盐 $\delta^{13} \mathrm{C}_{\mathrm{car}}$ 和 $\delta^{18} \mathrm{O}_{\mathrm{car}}$ 同 步减小表明湖区蒸降比减小和湖水盐度减小。该段 湖泊水位快速上升, 由粗颗粒风沙沉积转为细颗粒 湖相沉积, 气候条件整体较温暖湿润, 其中湿度条件 的改善可能比温度的升高更显著.

III b $6700 \sim 6200{ }^{14} \mathrm{C}$ a BP $(350 \sim 300 \mathrm{~cm}$; 湖相粉 砂质黏土)

湖区气候温暖干燥. 湖芯由黑色粉砂质黏土组 成, 湖芯粒径增至 $50 \mu \mathrm{m}$, 相应 $\delta^{13} \mathrm{C}_{\mathrm{org}}$ 值偏负, 指示 湖泊水位明显下降; 偏低的总有机碳含量表明区域 植被盖度降低; 湖芯中碳酸盐呈平缓峰值 $(24 \%)$, 指 
示湖区气温偏高; 碳酸盐碳氧同位素同步增大, 与其 他指标共同指示了湖泊收缩和盐度增大的暖干气候.

III c $6200 \sim 5400{ }^{14} \mathrm{C}$ a BP $(300 \sim 230 \mathrm{~cm}$; 碳酸钙 黏土质纹层)

温暖湿润的全新世气候最适宜期. 碳酸钙纹层 的出现需要沉积物的季节差异及保证纹层不受扰动 的不完全混合型湖泊 ${ }^{[38]}$. 夏季高温条件和水生植物 的繁茂生长使湖泊碳酸钙发生沉淀形成浅色层, 冬 季沉积有机质含量较高形成暗色层. 这段湖芯粒度 保持在 $25 \mu \mathrm{m}$ 左右且十分稳定, 也显示湖泊水位较高. 湖芯 $\delta^{13} \mathrm{C}_{\mathrm{org}}$ 值略有减小(偏负)和 $\mathrm{C} / \mathrm{N}$ 增至 14 可能指示 湖芯有机质中外源陆生 $\mathrm{C}_{3}$ 植物比重增加. 较高的总 有机碳含量表明湖区植被覆盖良好; 相应的碳酸盐 含量达到峰值 (30\%)指示温度较高. 略偏高的 $\delta^{18} \mathrm{O}_{\mathrm{car}}$ 值也指示温度较高, 而略偏低的 $\delta^{13} \mathrm{C}_{\mathrm{car}}$ 值指示湖水盐 度没有因为温度升高而升高. 即该时段的温度和降 水都比较高, 表明 $6200 \sim 5400{ }^{14} \mathrm{C}$ a BP是巴汗淖湖 区的中全新世适宜期. 值得一提的是, 这里的中全新 世适宜期 $\left(6200 \sim 5400{ }^{14} \mathrm{C}\right.$ a BP $)$ 似乎和黄土高原西部 的中全新世适宜期 $\left(6560 \sim 5790{ }^{14} \mathrm{C} \text { a BP }\right)^{[38]}$ 比较一 致. 砂质黏土)

II $5400 \sim 3700{ }^{14} \mathrm{C}$ a BP $(230 \sim 80 \mathrm{~cm} ;$ 湖相粉

气候总体温凉偏干. 沉积物由略偏红色的粉砂 质黏土组成, 平均粒径在 $100 \mu \mathrm{m}$ 上下较大幅度的波 动, 表明湖水位波动较大. 较粗的粒度和持续减小的 $\delta^{13} \mathrm{C}_{\mathrm{org}}$ 值共同指示湖泊水位下降. 该段湖芯有机碳含 量的略有下降表明湖区植被覆盖度下降, 偏低的 $\mathrm{C} / \mathrm{N}$ 值也可能指示陆源输入有机质的减少; 碳酸盐含量 先降低 $(230 \sim 170 \mathrm{~cm})$ 后上升 $(170 \sim 80 \mathrm{~cm})$ 指示气温 先下降后上升; 碳酸盐碳和氧同位素同步增加指示 湖区蒸降比增大, 湖水咸化. 温度与湖区有效湿度均 下降表明区域降水量减少，而且该段气候呈不稳定 状态, 例如, $4700 \sim 4600{ }^{14} \mathrm{C}$ a BP $(172 \sim 156 \mathrm{~cm}$; 图 3 所示的Event 1)和 $4200 \sim 3700{ }^{14} \mathrm{C}$ a BP(120 80 cm; 图 3 所示的Event 2 ) 存在两个相对温暖湿润的事件, 突出表现在沉积物粒径减小及碳酸盐含量增高, 碳 酸盐碳和氧同位素同步减小. 这一由中全新世气候 最适宜期向晚全新世干凉气候的过渡期(5400 3700

${ }^{14} \mathrm{C}$ a BP)也在黄土高原西部有较好的对应 $(5790 \sim 3800$ ${ }^{14} \mathrm{C}$ a BP) ${ }^{[39]}$.

I 约 $3700{ }^{14} \mathrm{C}$ a BP 以来 $(80 \sim 0 \mathrm{~cm}$; 砂层 $)$

$80 \mathrm{~cm}$ 厚的风成砂只表明约 $3700{ }^{14} \mathrm{C}$ a BP 以后巴
汗淖完全干涸. 由于年代的缺乏和地层的不连续, 无 法从这个湖芯中重建约 $3700{ }^{14} \mathrm{C}$ a BP 以来的湖区气 候变化. 目前正在研究邻近的染盖淖(图 1(b), 湖 6) 湖芯, 期望能够建立该区约 $4000{ }^{14} \mathrm{C}$ a BP 以来的气 候变化序列.

\section{3 讨论}

巴汗淖湖泊沉积物多指标的高分辨率气候记录 揭示, 约 $7650{ }^{14} \mathrm{C}$ a BP前后鄂尔多斯高原气候环境条 件发生明显变化, 由风沙沉积环境进入湖相沉积环 境, $7650 \sim 5400{ }^{14} \mathrm{C}$ a BP湖泊水位上升植被繁茂, 整 体为温暖湿润的气候期, 其中 $7650 \sim 6200{ }^{14} \mathrm{C}$ a BP气 候较温暖湿润, 湿度条件的改善胜于温度的上升, 而 温湿条件最佳期出现在 $6200 \sim 5400{ }^{14} \mathrm{C}$ a BP, 巴汗淖 湖相沉积物还记录了 $6700 \sim 6200{ }^{14} \mathrm{C}$ a BP湖泊水位 下降的暖干事件; 约 $5400{ }^{14} \mathrm{C}$ a BP后, 湖区温度和湿 度条件均开始恶化, $5400 \sim 3700{ }^{14} \mathrm{C}$ a BP湖泊水位下 降湖水咸化, 植被退化, 且气候波动明显, 虽 $4700 \sim$ $4600{ }^{14} \mathrm{C}$ a BP及 $4200 \sim 3700{ }^{14} \mathrm{C}$ a BP出现两个相对 暖湿的气候阶段, 但总体为凉干气候. 约 $3700{ }^{14} \mathrm{C} \mathrm{a}$ $\mathrm{BP}$ 前后, 巴汗淖彻底干涸, 其后沉积的砂层的年代 和沉积的连续性均无法确定, 故本文不作讨论. 巴汗 淖是鄂尔多斯高原串珠状分布的 7 个湖泊的终问湖, 其湖泊蓄水时间在 7 个湖泊中应该最短. 也就是说, 当全新世气候改善时, 作为终问湖的巴汗淖是 7 个串 珠湖中最后一个充水(约 $7650{ }^{14} \mathrm{C}$ a BP); 当全新世气 候恶化时, 它又是 7 个串珠湖中最早干涸的一个湖 (约 $3700{ }^{14} \mathrm{C}$ a BP). 换句话说, 巴汗淖湖泊记录的高 水位期 $\left(7650 \sim 3700{ }^{14} \mathrm{C}\right.$ a BP) 只是区域湿润气候期的 保守估计. 这里特别地提及一下全新世适宜期. 施雅 风等人 ${ }^{[40]}$ 将中国北方的全新世气候适宜期定义为大 暖期, 时间范围在 $8500 \sim 3000{ }^{14} \mathrm{C}$ a BP. 比较广泛 的土壤地层调查表明, $6000 \sim 5000{ }^{14} \mathrm{C}$ a BP鄂尔多斯

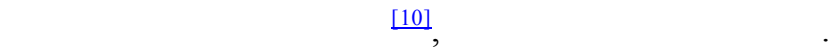
实际上中全新世温暖湿润气候可能存在于内蒙古高 原南部 ${ }^{[20]}$ 和黄土高原西部 ${ }^{[39,41,42]}$. 我们也注意到鄂 尔多斯高原盐海子 ${ }^{[15]}$ 和糜地湾剖面 ${ }^{[43]}$ 记录到的中全 新世暖干气候的证据似平与普遍存在于阿拉善高原 的中全新世暖干气候证据一致 ${ }^{[44,45]}$, 但在作出合理 的气候解释之前, 鄂尔多斯高原出现的关于中全新 世气候的不相容证据值得进一步地研究.

致谢 特别感谢张成君、高尚玉、张虎才、吴敬禄、任国 玉和钟巍老师对本文完成提供的指导和建设性意见. 


\section{参考文献}

1 Overpeck $\mathrm{J}$ T. The role and response of continental vegetation in the global climate system. In: Eddy J A, Oescheger H. eds. Global Changes in the Perspective of the Past. Indianapolis: John Wiley and Sons Inc, 1993. 221-238

2 Rind D, Overpeck J. Hypothesized causes of decade-to-centuryscale climate variability: Climate model results. Quat Sci Rev, 1993, 12: 357-374[DOI]

3 Bradley R. 1000 years of climate change. Science, 2000, 288: 13531355[DOI]

4 Crowley T J. Causes of climate change over the past 1000 years. Science, 2000, 289: 270-277[DOI]

5 Hoerling M P, Hurrell J W, Xu T. Tropical origins for recent North Atlantic climate change. Science, 2001, 292: 90-92[DOI]

6 靳鹤龄, 董光荣, 苏志珠, 等. 全新世沙漠-黄土边界带空间格 局的重建. 科学通报, 2001, 46(7): 538-543

7 董光荣, 靳鹤龄, 陈惠忠. 末次间冰期以来沙漠-黄土边界带移 动与气候变化. 第四纪研究, 1997, 2: 158-167

8 Sun J M, Ding Z L. Deposits and soils of the past 130,000 years at the desert-loess transition in northern China. Quat Res, 1998, 50: 148 -156[DOI]

9 Sun J M, Ding Z L, Liu T S, et al. 580,000-year environmental reconstruction from Aeolian deposits at the Mu Us Desert margin, China. Quat Sci Rev, 1999, 18: 1351-1364[DOI]

10 高尚玉, 陈渭南, 靳鹤龄, 等. 全新世中国季风区西北缘沙漠演 化初步研究. 中国科学 B 辑, 1993, 23(2): 202-208

11 Zhou W J, Head M J, Deng L. Climate changes in northern China since the late Pleistocene and its response to global change. Quat Int, 2001, (83-85): 285-292

12 Zhou W J, Dodson J, Head M J, et al. Environmental variability within the Chinese desert-loess transition zone over the last 20 000 years. Holocene, 2002, 12(1): 117-122

13 周杰, 周卫健, 陈惠忠, 等. 新仙女木时期东亚夏季风降水不稳 定的记录. 科学通报, 1999, 44(2): 205-208

14 董光荣, 王贵勇, 李孝泽, 等. 末次间冰期以来我国东部沙区的 古季风变迁. 中国科学 D 辑: 地球科学, 1996, 26(5): 437-444

15 Chen C-T A, Lan H C, Lou J Y, et al. The dry Holocene Megathermal in Inner Mongolia. Paleogeogr Paleoclimatol Paleoecol, 2003, 193(2): 181-200[DOI]

16 钱林清. 黄土高原气候. 北京: 气象出版社, 1991. 24-26

17 王文辉. 内蒙古气候. 北京: 气象出版社, 1990.19-21

18 郑喜玉. 内蒙古盐湖. 北京: 科学出版社, 1992. 195-202

19 任国玉. 内蒙古湖相沉积 ${ }^{14} \mathrm{C}$ 年代测定中 硬水” 影响的发现. 湖 泊科学, 1998, 10(3): 80-82

20 Feng Z D, Wang W G, Guo L L, et al. Lacustrine and eolian records of Holocene climate changes in the Mongolian Plateau: Preliminary results. Quat Int, 2005, 136: 25-32[DOI]

21 Stuiver M, Rimer P J, Bard E, et al. INTCAL 98 radiocarbon age calibration, 240000 cal. Radiocarbon, 1998, 40: 1041-1083

22 Last W M, Teller J T. Paleolimnology of Lake Manitoba, Canada: The lithostratigraphic evidence. Geogra Phys Quat, 2004, 56: 135154

23 陈敬安, 万国江, 张峰, 等. 不同时间尺度下的湖泊沉积物环境 记录一以沉积物粒度为例. 中国科学 D 辑: 地球科学, 2003, 33(6): $563-568$

24 Shen J, Lin X Q, Wang S M, et al. Palaeoclimatic changes in the Qinghai Lake area during the last 18,000 years. Quat Int, 2005, 136: $131-140$

25 王国安. 稳定碳同位素在第四纪古环境研究中的应用. 第四纪
研究, 2003, 23(5): 471-484

26 张成君, 陈发虎, 尚华明, 等. 中国西北干旱区湖相沉积物中有 机质碳同位素组成的环境意义一以民勤盆地三角城古湖泊为例. 第四纪研究, 2004, 24(1): 88-94

27 陈敬安, 万国江, 汪福顺, 等. 湖泊现代沉积物碳环境记录研究. 中国科学 D 辑: 地球科学, 2002, 32(1): 73-80

28 Lee X Q, Feng Z D, Guo L L, et al. Carbon isotope of bulk organic matter: A proxy for precipitation in the arid and semiarid central East Asia. Glob biogeochem cycles, 2005, 19(4): GB4010 .1-8

29 Hodell D A, Brenner M, Kanfoush S L, et al. Paleoclimate of Southwestern China for the past 50,000 yr inferred from lake sediment records. Quat Res, 1999, 52: 369-380[DOI]

30 Stuiver M. Oxygen and carbon isotope ratios of freshwater carbonate as climatic indicators. J Geophys Res, 1970, 75: 5247-5257

$31 \mathrm{Li} \mathrm{H} \mathrm{C,} \mathrm{Ku} \mathrm{T} \mathrm{L.} \delta^{13} \mathrm{C}-\delta^{18} \mathrm{O}$ covariance as a paleohydrological indicator for closed-basin lakes. Palaeogeogr Palaeoclimatol Palaeoecol, 1997, 133: 69-80[DOI]

32 Frogley M R, Tzedakis P C, Heaton T H E. Climate variability in NW Greece during the last interglacial. Science, 1999, 285: 18861889 [DOI]

33 Gasse F, Fontes J C, Plaziat J C, et al. Biological remains, geochemistry and stable isotopes for the reconstruction of environmental and hydrological changes in the Holocene lakes from North Sahara. Palaeogeogr Palaeoclimatol Palaeoecol, 1987, 60: 1-46[DOI]

34 Talbot M R. A review of the palaeohydrological interpretation of carbon and oxygen isotopic ratios in primary lacustrine carbonates. Isotope Geosci, 1990, 80: 261-279[DOI]

35 Rhodes T E, Gasse F, Lin R F, et al. A late Pleistocene-Holocene lacustrine record from Lake Manas, Zunggar (northern Xinjang, Western China). Palaeogeogr Palaeoclimatol Palaeoecol, 1996, 120: 105-121[DOI]

36 吴敬禄, 王苏民, 潘红玺, 等. 青藏高原东部 RM 孔 $140 \mathrm{ka}$ 以来 湖泊碳酸盐同位素记录的古气候特征. 中国科学 D 辑: 地球科 学, 1997, 27(3): 255-259

37 Bowen R. Isotopes and climates. London: Elsevier Applied Science, 1991. 483

38 Peck J A, Khosbayar P, Fowell S J, et al. Mid to late Holocene climate change in north central Mongolia as recorded in the sediments of Lake Telmen. Palaeogeogr Palaeoclimatol Palaeoecol, 2002, 183: 135-153[DOI]

39 An C B, Feng Z D, Barton. Dry or humid? Mid-Holocene humidity changes in arid and semi-arid China. Quat Sci Rev, 2006, 25: 351$361[\mathrm{DOI}]$

40 施雅风, 孔昭宸. 中国全新世大暖期气候与环境. 北京: 海洋出 版社, 1992

41 Feng Z D, An C B, Jull A J T, et al. Stratigraphic evidence of the mid-Holocene Megahumid climate in the western part of the Chinese Loess Plateau. Glob Planet Change, 2004, 43: 145-155[DOI]

42 Feng Z D, An C B, Wang H B. Holocene climatic and environmental changes in the arid and semi-arid areas of China: A review. Holocene, 2006, 16(1): 1-12[DOI]

43 Li X Q, Zhou W J, An Z S, et al. The vegetation and monsoon variations at the desert-loess transition belt at Midiwan in northern China for the last $13 \mathrm{ka}$. Holocene, 2003, 13(5): 779-784[DOI]

44 陈发虎, 吴巍, 朱艳, 等. 阿拉善高原中全新世干旱事件的湖泊 记录研究. 科学通报, 2004, 49(1): 1-9

45 Herzschuh U, Tarasov P, Wünnemann B, et al. Holocene vegetation and climate of the Alashan Plateau, NW China, reconstructed from pollen data. Palaeogeogr Palaeoclimatol Palaeoecol, 2004, 211: $1-17[\mathrm{DOI}]$ 